\title{
PERSPEKTIF KONSERVASI ARSITEKTURAL PADA MASYARAKAT JAWA
}

\author{
Johannes Adiyanto \\ Program Studi Teknik Arsitektur, Universitas Sriwijaya \\ Jl. Raya Palembang-Prabumulih KM 32 Inderelaya, Sumatera Selatan \\ Email: johannesadiyanto@ft.unsri.ac.id atau johannesadiyanto@yahoo.com
}

\begin{abstract}
Abstrak
Umumnya pada bangunan tradisional di Indonesia banyak menggunakan kayu sebagai material utamanya. Konsekuensi dari material ini pada iklim tropis lembab adalah mudah lapuk. Bangunan memerlukan perawatan dan penggantian material secara lebih sering dibandingkan dengan bangunan dengan material batu. Fokus kajian ini adalah pada bangunan rumah masyarakat Jawa. Pada naskah primbon, perbaikan rumah setara dengan pembuatan rumah baru, dan tidak hanya menyangkut masalah teknis tapi juga kaitan rumah dengan alam dan cita-cita penghuni di masa depan. Dengan pemahaman tersebut bagaimana pemahamanan konservasi di masyarakat Jawa? Subyek kajian adalah naskah Jawa tentang bangunan (primbon, kawruh kalang dan kawruh griya). Metode yang digunakan adalah metode hermeneutik dari Paul Ricouer. Dengan tiga tahapan yaitu tahap pertama 'konstruksi' pemahaman konservasi dalam budaya Jawa dengan metode analisis konten. Tahap kedua adalah validasi dari pemahaman tersebut dengan menghadirkan kasus Dusun Ngibikan. Tahap ketiga adalah tahapan diskusi dengan melakukan penyandingan aspek filsafati dari pemikiran Ricouer tentang 'history, memory and forgetting'. Kajian eksplorasi ini menunjukkan bahwa bagi masyarakat Jawa konservasi tidak hanya tentang bangunan. Dalam filsafat Jawa bahwa hidup adalah sekedar singgah minum, sehingga konservasi adalah sebuah proses, bukan hasil; konservasi bersifat dinamis dan berubah, bukan sesuatu yang permanen dan tetap.
\end{abstract}

Kata kunci: naskah jawa, metode hermeneutik dan konservasi.

\begin{abstract}
Title: Architectural Conservation Perspective In Javanese Community

Traditionally, Indonesian, with tropical climate, use wooden material for their building. The consequences of that material and the tropical climate is building cannot durable compare stone material. The building needs renewal more frequently and sometimes reconstruction.This study focus in Java building (houses) and their culture. In Javanese manuscripts (primbon), repairing the house is the same level with build the new one. To repair or to build the house for Javanese is not only the technical aspect (like structure or the form), but also about the connection with nature and their expectation in the future. Based on that understanding what the meaning of the conservation in Javanese culture? The subject for this study is architectural Javanese manuscripts (Primbon, Kawruh Kalang, and Kawruh Griya). This study uses hermeneutics method by Paul Ricouer. There are three steps: step one is to build the conservation understanding in Javanese culture, using content analysis. Step two is validation. This step using Ngibikan Village for case study. Step three is discussion. This step exploring the philosophical aspect in Javanese culture and compare with Ricouer thinking about 'history,memory and forgetting'. The result of this exploration studies that for Javanese culture, conservation not only discuss about building. Based on Javanese philosophy that live only 'stop' for drink (urip mung mampir ngombe), the conservation is a process, not result; the conservation is dynamic or change, not permanent or unchanged.
\end{abstract}

Keywords: architectural Javanese manuscripts, hermeneutic method and conservation. 


\section{Pendahuluan}

Material dalam arsitektur pada tahun 2014 menjadi perbincangan yang cukup ramai dibicarakan disebabkan keikutsertaan Indonesia dalam International Architecture Exhibition ke 14 di Venesia. Topik yang diangkat adalah "Ketukangan: Kesadaran Material". Rem Koolhaas, sebagai kurator utama kegiatan ini, mengajak tiap negara untuk melakukan napak tilas, menelusuri dan menggali kejadian-kejadian, informasi-informas, srta pengalaman-pengalaman yang terjadi dalam khazanah arsitektur masing-masing (Armand, Sopandi, Hutama, Hartanto, \& Tardiyana, 2014, hal. 12). Tim kurator Indonesia menjelajahi material-material yang pernah mengisi kesejarahan arsitektural di Indonesia yaitu kayu, batu bata, baja, beton dan bambu.

Pada pembahasan kayu dinyatakan bahwa: "Tradisi membangun dengan kayu telah mengakar dan secara luas menjadi pengetahuan umum dalam masyarakat. Namun demikian, pengetahuan tradisional di Indonesia selalu diturunkan secara lisan; catatan tertulis mengenainya baru hadir setelah awal abad-19, yang kemudian besar karena pengeruh kehadiran bangsa Belanda" (Armand, Sopandi, Hutama, Hartanto, \& Tardiyana, 2014, hal. 26)

Material kayu menjadi material utama karena Indonesia mempunyai hutan hujan tropis dengan luas $52,4 \%$ luas wilayah indonesia dan memiliki 4.000 jenis pohon yang berpotensi untuk digunakan sebagai kayu bangunan, akan tetapi baru 400 jenis yang diidentifikasi memiliki nilai ekonomi dan 260 jenis diantaranya digolongkan sebagai kayu perdagangan (Armand, Sopandi, Hutama, Hartanto, \& Tardiyana, 2014, hal. 24).
Dalam tradisi Jawa, terdapat dua jenis naskah/literatur yang menegaskan peran sentral material kayu - terutama kayu jati - dalam arsitektur Jawa yaitu: kawruh griya yang merupakan panduan bagi calon pemilik rumah; dan kawruh kalang yang merupakan manual book bagi para tukang, terutama tukang kayu dalam proses pendirian bangunan. (Armand, Sopandi, Hutama, Hartanto, \& Tardiyana, 2014, hal. 26).

Hal yang perlu diperhatikan adalah bahwa Indonesia berada di iklim tropis lembab yang mempunyai karakteristik tertentu, seperti pada tabel berikut

Tabel 1. Karakteristik Zona Tropis Lembab Ekuator

\begin{tabular}{|l|l|l|l|l|}
\hline ZONE & $\begin{array}{l}\text { Approxi- } \\
\text { mate } \\
\text { latitude } \\
\text { range }\end{array}$ & $\begin{array}{l}\text { Natural } \\
\text { vegeta- } \\
\text { tion }\end{array}$ & $\begin{array}{l}\text { Typical } \\
\text { cultiva- } \\
\text { tion }\end{array}$ & Climate \\
\hline $\begin{array}{l}\text { Warm } \\
\text { humid } \\
\text { equa- } \\
\text { torial }\end{array}$ & $\begin{array}{l}7 \mathrm{k} / 2 \mathrm{~S}- \\
\mathrm{S}\end{array}$ & $\begin{array}{l}\text { Tropical } \\
\text { rain } \\
\text { forest }\end{array}$ & $\begin{array}{l}\text { Banana, } \\
\text { palm } \\
\text { oil }\end{array}$ & $\begin{array}{l}\text { Warm } \\
\text { with } \\
\text { high } \\
\text { humidity } \\
\text { and } \\
\text { rainfall }\end{array}$ \\
\hline
\end{tabular}

Sumber: Diolah dari Evans, 1999

Dengan karakteristik iklim di Indonesia dengan kelembaban tinggi (antara 30\% sampai $98 \%$, tergantung pada lokasi) dan hujan (hingga 700mm per tahun) (Prianto, Bonneaud, Depecker, \& Peneau, Vol 1, Number 2, 2000); maka tingkat kelapukan material kayu amat sangat dimungkinkan. Konsekuensinya penggantian elemen arsitektural pada rumah secara periodik dilakukan.

Disisi lain, menurut UU no 11 Tahun 2010 tentang Cagar Budaya Pasal 1 ayat 28 dinyatakan bahwa:

Pemugaran adalah upaya pengembalian kondisi fisik Benda Cagar Budaya, Bangunan Cagar Budaya, dan Struktur Cagar Budaya yang rusak sesuai dengan keaslian bahan, bentuk, tata letak, dan/atau teknik pengerjaan untuk memperpanjang usianya. 
Pengertian Undang-undang diatas adalah mengacu pada pemahaman dasar tentang konservasi yang diungkapkan oleh Filden yang menyatakan "...Conservation consists of actions taken to prevent decay, and within this objective it also includes management of change and presentation of the object so that the objects' messages are made comprehensible without distortion".. Feilden kemudian menjelaskan lebih lanjut bahwa konservasi arsitektural jauh lebih kompleks karena (1) bangunan harus berdiri terus; (2) faktor ekonomis; (3) bangunan sangat terpengaruh kondisi cuaca; (4) perlu kolaborasi lintas ilmu dalam mengerjakan konservasi bangunan (Feilden, 2003, hal. vii).

Forsyth secara bijak menyatakan bahwa:

Every building, however humble, possesses a history, and buildings from different periods and regions are unique. All historic buildings undergo cycles of alteration in their lifetime. Typically, minor repairs are carried out periodically, with programmes of major maintenance, renovation and modification taking place at less frequent intervals. This pattern may alternate with periods of relative inactivity and perhaps neglect. Major changes are usually made to buildings to modify or extend their use, to update their style, and particularly to repair $f i$ re damage. (Forsyth, 2007, hal. 5)

Dengan pengertian-pengertian dasar diatas, kertas kerja ini mencari jawab atas pertanyaan: bagaimanakah bangunan Jawa mempertahankan keberadaannya? lalu apakah kegiatan tersebut termasuk dalam pemahaman konservasi, baik dalam pemahaman undang-undang maupun dalam pemahaman umum?

\section{Metode}

Metode studi eksplorasi ini menggunakan hermenutik Ricouer, yang disebutnya sebagai hermenutical phenomenology (Ricouer, 1975). Hermeneutic phenomenology, being the process of interpreting and describing human experience to understand the central nature of that experience, is well positioned as a suitable methodology for human sciences research... Hermeneutic phenomenology is not a method of research but, rather, both a theoretical perspective and a methodology, a strategy or plan that lies behind the method employed in a particular study (Tan, Wilson, \& Olver, 2009).

Tan dan kawan-kawan lebih lanjut menjelaskan bahwa ada tiga tahapan dalam hermeneutik fenomenologi yaitu: Explanation, interpretation, and understanding.

Pada studi eksplorasi ini juga terbagi atas tiga tahapan, yang didasarkan pada pemahaman tiga tahapan diatas yaitu: tahap pertama 'konstruksi' pemahaman konservasi dalam budaya Jawa dengan metode analisis konten. Tahap kedua adalah validasi dari pemahaman tersebut dengan menghadirkan kasus Dusun Ngibikan. Tahap ketiga adalah tahapan diskusi dengan melakukan penyandingan aspek filsafati dari pemikiran Ricouer tentang 'history, memory and forgetting'.

\section{Pemahaman Konservasi Arsitektural Jawa}

\section{Konstruksi Pemahaman}

Pada tahapan pemahaman yang mengkontruksi pemahaman konservasi Jawa dihadirkan beberapa naskah yang 
memuat pengertian dan cerita tentang proses perbaikan rumah.

Pada naskah Primbon Betaljemur Adammakna dinyatakan bahwa 'mendirikan' rumah adalah proses yang setara dengan 'perbaikan' rumah, seperti yang termuat pada pasal 177 dan 178, sebagai berikut:

177.Petungan ngedeake utawa ndandani omah

Miturut wiwite dina lan pasarane, neptune digunggung banjur kapetung, kerta, yasa, candhi, rogoh, sempoyong. Yen tiba: kerta, oleh kasugihan, yasa bisa kuwat, candhi, rahayu slamet, rogoh, sring kelangan, sempoyong, sring ngalih adoh utawa ora awet.

178. Petung ngedeake utawa ndandani omah

Minurut wiwite dina lan pasarane, neptune digunggung banjur kapetung : sri, kitri, candhi, rogoh, sempoyongan. Yen tiba: sri, sugih dhayoh. Kitri, karejeken, werdi, sugih anak. Candhi keringan. Rogoh, sring kemalingan. Sempoyong, sring kapaten. (Tjakraningkrat, 2013).

Secara bebas dapat diartikan sebagai berikut:

177. Perhitungan mendirikan rumah atau memperbaiki rumah

Menurut awalnya hari dan pasaran, neptu (nilai jumlah angka dari suatu hari dan pasaran), dijumlahkan lalu diperhitungkan pada kerta, yasa, candhi, rogoh, sempoyang.

Jika jatuh pada: kerta, mendapat kekayaan; yasa, mendapatkan kekuatan; candhi mendapatkan keselamatan; rogoh, sering terjadi kehilangan; sempoyong, sering berpindah jauh atau tidak tahan lama.

178. Perhitungan mendirikan atau memperbaiki rumah.
Menurut awalnya hari dan pasaran, neptu dijumlahkan lalu diperhitungan pada sri, kitri, candhi, rogoh, sempoyongan.

Jika jatuh pada sri, sering mendapatkan tamu; kitri, mendapatkan rejeki,mendapatkan kebaikan, banyak anak; candhi mendapatkan kekeringan; rogoh sering tertimpa kecurian; sempoyongan sering tertimpa kematian.

Dari naskah Primbon terungkap bahwa kedudukan memperbaiki rumah dan mendirikan rumah setara. Disamping itu ternyata dalam proses perbaikan/ membangun rumah terdapat 'prediksi' di masa depan. Kejadian tertentu akan terjadi jika perhitungannya jatuh pada watak tertentu. Prijotomo menggarisbawahi bahwa:

"Primbon bukan memberikan kepastian akan adanya efek psikologik(al) tertentu, tetapi memanfaatkan (meng'antisipasi') efek psikologik(al) sebagai sebuah alat untuk menyampaikan atau mengkomunikasikan penggal demi penggal aturan dan tatanan arsitektur. (Prijotomo, 2004, hal. 63-65).

Pada naskah Kawruh Griya Kapatihan 1882 (merupakan sumber utama dari Disertasi Josef Prijotomo) diceritakan pada bagian pambuka bahwa pada masa kuno, griya orang Jawa dibuat dari batu. Tetapi kemudian diubah menjadi bermaterial kayu karena lebih ringan, tidak membahayakan dan mudah dalam pengerjaannya. Sambungan pada konstruksi bermaterial batu mempunyai kelemahan pada sendi-sendi sambungan yang menjadi alur atau aliran air, sehingga akan retak dan rusak. Akibatnya bangunan akan rubuh. Jika bermaterial batu, maka bangunan akan rubuh secara bersamaan dan membahayakan penghuninya, 
sedangkan jika bermaterial kayu, akan mudah dalam proses penggantian bagian yang lapuk dan tidak akan rubuh secara bersamaan. Bagian yang paling awal diubah dari batu ke kayu adalah bagian atap, sedangkan bagian dinding masih bermaterial batu. Namun sejalan berjalannya waktu, dinding juga diubah dengan material kayu. (Prijotomo, 2006, hal. 303-304). Kayu yang dipilih juga mempunyai berbagai ketentuan.

Menurut kepercayaan orang Jawa, pohon jati itu mempunyai angsar (= daya pengaruh) baik dan buruk. Yang memiliki angsar baik bisa membawa banyak rejeki, keselamatan dan sebagainya. Sebaliknya, yang angsarnya jelek, dapat mendatangkan kemelaratan, kecelakaan dan sebagainya (Prijotomo, 2006, hal. 305). Interpretasi yang bisa dilakukan terhadap naskah Kawruh Griya ini adalah bahwa karena iklim (curah hujan yang cukup tinggi) maka konsekuensinya material pembentuk hunian perlu sering diperbaiki/ diperbaharui. Material batu ternyata juga rentan terhadap curah hujan yang tinggi, dan juga membawa akibat pada keselamatan penghuninya. Jadi dipilihlah kayu sebagai material atapnya, karena mudah pengerjaannya dan lebih ringan sehingga tidak terlalu berbahaya. Disamping itu juga kayu mempunyai angsar (=daya pengaruh) kepada pemiliknya dikemudian hari.

Disini ada konteks iklim yang mendorong pemilihan material bahan bangunan; terdapat perubahan material walau secara bentuk masih tetap sama (....pada waktu itu sudah banyak sendisendi persambungan yang retak, hanya bentuknya saja yang tetap asli yaitu bangunan yang diberi nama: candrakini... (Prijotomo, 2006, hal. 304)), dan ada pertimbangan kemudahan penggantian dan keamanan. Material kayu juga mempunyai pengaruh pada kehidupan penghuninya disuatu saat nanti, sehingga perlu dilakukan pemilihan kayu yang cermat.

Pada naskah kawruh kalang mengatakan secara langsung tentang 'perbaikan' atau daya pengaruh material bahan bangunan. Kawruh kalang - Sastrawirjatmo secara khusus ditulis bertujuan sebagai 'panduan' para tukang. Disamping itu secara khusus naskah ini ditulis ulang dan dipublikasikan karena banyaknya, saat itu, orang Jawa terpikat dengan proses pembangunan barat. (Prijotomo, 2006, hal. 337- 338). Namun pada naskah ini terungkap bahwa sistem konstruksi bangunan Jawa amat mudah di 'lepaspasang'. Contoh pada bab V ada bahasan tentang pembuatan sunduk. "Sunduk yang dimasukkan dalam sakaguru itu memiliki sundung pamanjang yang sama dengan panjang dari pamidhangan pamanjang, lebarnya disamakan dengan tebal dari midhangan tadi, sedang tebal dari sunduk adalah seperemat kurangnya dari tebal midhanga". (Prijotomo, 2006, hal. 349). Sunduk berfungsi 'pengunci' hubungan antara sistem struktur, namun tidak seperti paku yang sistem strukturnya 'rigid' (struktur rangka kaku) tapi dengan sunduk maka sistem strukturnya menjadi sistem 'goyang/lentur' (struktur rangka lentur). Di satu sisi sistem struktur rangka lentur ini sesuai dengan kondisi geografis di Jawa yang sering terjadi gempa. Disini bangunan akan ikut 'bergoyang' dengan 'gempa', disini konsep 'kuat lentur' bukan 'kuat kaku' seperti sistem struktur yang biasa digunakan pada bangunan kolonial. 
Namun hal lain yang bisa dipelajari disini adalah dengan adanya sistem sunduk maka tiap bagian dari bangunan bisa di 'lepas-pasang' secara 'mandiri' tanpa harus kuatir bangunan akan rubuh atau mempengaruhi sistem struktur yang lain. Konsep 'lepaspasang' ini merupakan solusi jika ada satu sistem struktur yang sudah lapuk dan perlu dilakukan perbaikan atau penggantian.

Dengan hadirnya primbon, kawruh griya dan kawruh kalang, terjabarkan bahwa proses perbaikan bangunan Jawa setara dengan pendirian bangunan 'baru', material kayu dipilih karena lebih ringan daripada material kayu, iklim tropis (curah hujan dan panas sinar matahari) akan mempercepat lapuknya material bahan bangunan sehingga akan sering dilakukan perbaikan dan penggantian material tersebut, dan sistem struktur yang digunakan juga mendukung terjadinya perbaikan dan penggantian tersebut.

\section{Validasi Pemahaman}

Naskah-naskah diatas perlu di validasi dengan kasus arsitektural. Untuk kasus yang dihadirkan adalah proses rekonstruksi Dusun Ngibikan. Jabaran proses rekonstruksi Dusun Ngibikan telah dijelaskan oleh Adiyanto pada Journal Nakhara (Adiyanto, Vol. 7 October 2011).

Pada kasus Dusun Ngibikan, masyarakat melakukan rekonstruksi 'ruang hidupnya' dari material-material yang tidak hancur akibat gempa, yang sebagian besar berupa material kayu. Dusun Ngibikan merupakan dusun tempat mandor dan tukang kayu yang biasa mengikuti Eko Prawoto, seorang arsitek profesional. Kemampuan dasar ini amat berguna dalam proses rekonstruksi ini. Eko Prawoto dan Maryono, mandor yang biasa bekerja dengan Eko Prawoto, mengambil prakarsa dalam proses rekonstruksi ini. Didukung dengan bantuan dari harian Kompas, Eko Prawoto, Maryono dan masyarakat Dusun Ngibikan melakukan proses rekonstruksi hunian mereka.

Bentuk rumah yang dipakai sebagai 'modul' dasar hunian mengambil bentuk atap rumah kampung dengan bahan penutup atap non-asbestos fiber cement dengan pertimbangan lebih ringan dibanding dengan genteng 'kodok' yang dulu mereka gunakan.

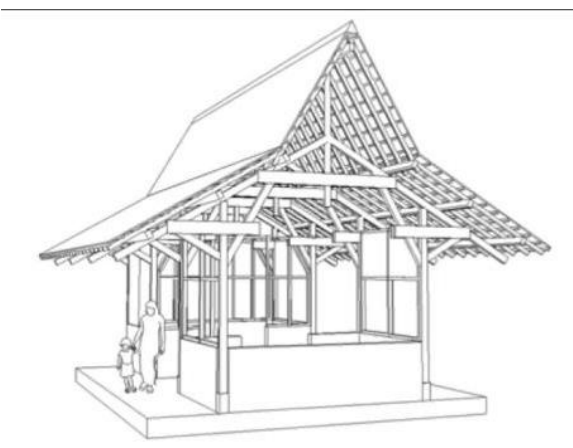

Gambar 1 Model rumah rekonstruksi Dusun Ngibikan

Sumber: Prawoto, 2010, http://ruang17.wordpress.com/2010

Bentuk dasar itu tidaklah baku, tapi penghuni dapat mengkreasikan dan berkreasi dengan material yang ada. Dalam kasus Dusun Ngibikan, proses rekonstruksi akibat gempa menggunakan material kayu, karena pada saat itu material kayu tidak hancur karena gempa seperti halnya material batu bata. Kayu dengan mudah dibentuk ulang dan digunakan kembali sebagai konstruksi utama sebuah hunian. Bentuk hunian juga menyesuaikan dengan material yang ada. Inspirasi bentuk hunian adalah atap rumah kampung dengan beberapa modifikasi, antara lain adalah penutup atap yang lebih ringan dari material 
yang digunakan sebelum terjadinya gempa.

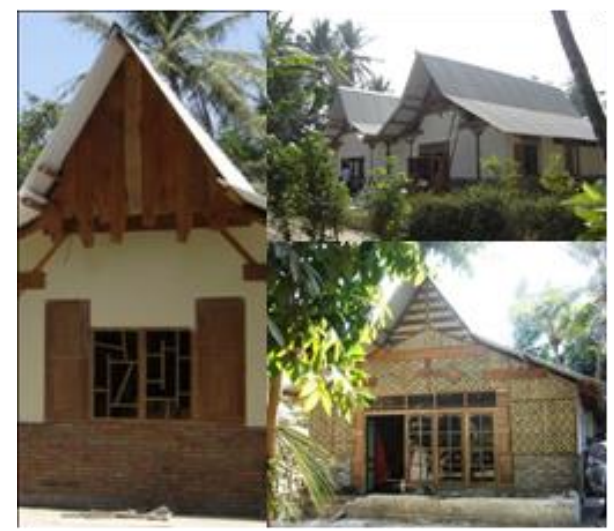

Gambar 2 Beberapa kombinasi rumah hasil rekonstruksi

Sumber: Pangarsa, 2008

Jika dikaitkan dengan bahasan sebelumnya yang mengungkap pemikiran-pemikiran berdasarkan naskah Jawa. Kasus Ngibikan membuktikan beberapa hal, antara lain proses rekonstruksi merupakan proses pembangunan rumah 'baru'. Proses pembangunan 'baru' ini terbukti dengan adanya beberapa ritual yang biasa dilakukan dalam proses pendirian rumah baru, antara lain ritual slametan saat proses kontruksi atap telah selesai.

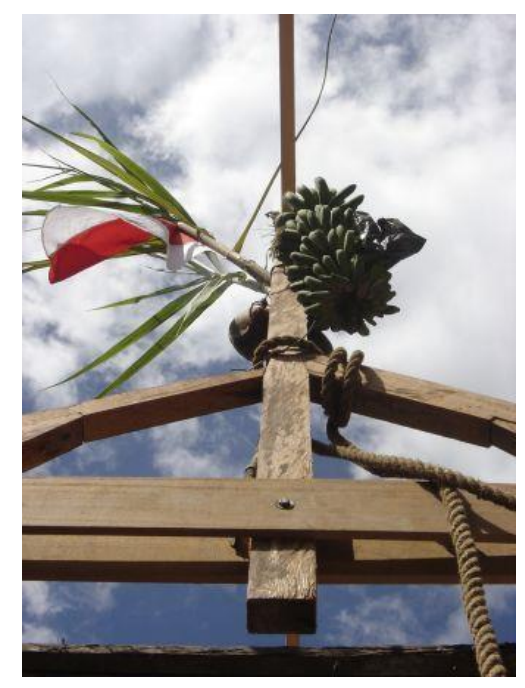

Gambar 3 Ritual Slametan pada rekonstruksi hunian di Dusun Ngibikan Sumber: : Prawoto, 2010, http://ruang17.wordpress.com/2010

\section{Diskusi}

Di tahap diskusi ini dipertanyakan bagaimana pola pikir 'perbaikan' bagi masyarakat Jawa itu sendiri, apa yang seharusnya dipertahankan dan apa yang boleh diubah, dalam konteks konservasi.

Dalam konteks konservasi ada hal yang dipertahankan ada hal yang diabaikan. Kwanda menyatakan bahwa terdapat dua teori konservasi, yaitu:

Teori pertama dikenal sebagai teori klasik konservasi yang berkembang di Eropa sejak abad 19, dan berpandangan bahwa keberadaan nilai penting suatu objek terlepas dari masyarakatnya yang tidak boleh mengalami perubahan apapun, seperti tercermin pada Manifesto SPAB (1877).

Teori kedua dikenal dengan teori kontemporer berkembang pada tahun 1980an yang melihat pusaka budaya harus berakar pada masyarakat yang menciptakan, memberi makna, dan yang memutuskan bangunan apa yang dapat dipilih sebagai bangunan pusaka budaya. (Kwanda, 2013).

Hal yang menarik adalah kedua teori ini mempunyai kesamaan pada pemahaman 'mempertahankan'. Jika dikaitkan dengan proses 'perbaikan' bangunan Jawa, seperti yang terjadi di Ngibikan, apakah rekonstruksi hunian di dusung Ngibikan bukan sebagai sebuah proses/usaha konservasi?

Pada keadaan inilah pemahaman filosofis bisa menjelaskan hal tersebut. Ricouer secara khusus menulis buku tentang memory, history and forgetting. Memori adalah sebuah 'pemanggilan kembali' kejadian masa lalu '...the memory is said to arise as the presence of the absent" (Ricoeur, 2004, hal. 38). Memori tidak terkait dengan waktu tertentu (Ricoeur, 2004, hal. 6). Hal ini 
berbeda dengan history /sejarah yang mempunyai kaitan dengan tempat (Ricoeur, 2004, hal. 149) dan bersifat kronologis (dalam ruang lingkup waktu tertentu) dan tercatat/tertulis (Ricoeur, 2004, hal. 138). Bagaimana dengan 'melupakan/ forgetting?

There is forgetting wherever there had been a trace. But forgetting is not only the enemy of memory and of history. One of the these to which I am most attached is that there also exists a reserve of forgetting, which can be a resource for memory and for history, although there is no way to draw up a score sheet for this battle of the giants. This double valence of forgetting is comprehensible only if the entire problematic of forgetting is carried to the level of the historical condition that underlies the totality of our relations to time. Forgetting is the emblem of the vulnerability of the historical condition taken as a whole. (Ricoeur, 2004, hal. 284)

Proses melupakan/forgetting tidak benar-benar anti sejarah atau memori tapi menyisakan 'jejak'/trace yang bisa digunakan untuk dasar keterkaitan dengan masa sebelumnya.

Jabaran Ricoeur ini membuktikan bahwa proses mengenang dan menghormati sejarah tidak harus dengan 'membekukan' bangunan atau kawasan bersejarah tersebut. Pembelajaran tentang kehidupan bukan saja berada di masa lalu, dan pembelajaran tersebut bukan saja dengan cara 'membekukan' tapi juga menghargai proses. Ricouer mengutip pernyataan Nietzche yang mengatakan: "..believe that the meaning of existence will come ever more to light in the course of a 'process' they look backward only to understand the present by observation of the prior process and to learn to desire the future even more keenly; they have no idea how ahistorically they think and act despite all their history, nor that their concern with history stands in the service, not of pure knowledge, but of life" (Ricoeur, 2004, hal. 289)

Sejarah dipelajari untuk tidak hanya semata untuk pengetahuan tetapi untuk kehidupan. Jika konservasi hanyalah sebuah usaha 'membekukan' dan tidak terkait dengan masa depan, maka kegiatan konservasi hanyalah kegiatan pengarsipan belaka. Hal pengarsipan sebenarnya juga berguna untuk masa depan, sebab pengarsipan tidak mengulang kejadian masa lalu tapi persiapan kita untuk merespon masa depan.

"...the question of the archive is not, we repeat, a question of the past. This is not the question of a concept dealing with the past which might already be at our disposal or not at our disposal, an archivable concept of the archive. It is a question of the future, the question of the future itself, the question of a response, of a promise and of a responsibility for tomorrow" (Derrida, Vol. 25, No. 2, 1995).

Jika kita kembalikan ke kejadian rekonstruksi Dusun Ngibikan, yang dilakukan oleh warga dusun adalah sebuah proses melangkah ke depan berdasarkan kejadian masa lampau. Penentuan material atap yang lebih ringan dari yang digunakan sebelumnya, konstruksi kayu yang diambil dari sisa-sisa bangunan akibat gempa adalah sebuah proses 'konservasi' masyarakat Jawa. Menggunakan 'jejak' memori akan masa lalu untuk menatap masa depan. Hal ini setara dengan jabaran Primbon yang menyatakan angsar (daya 
pengaruh) material kayu terhadap kehidupan di masa depan.

Jadi bagi masyarakat Jawa, konservasi bukan hanya sekedar 'membekukan' bangunan, akan tetapi lebih pada proses kehidupan selanjutnya. Proses perbaikan rumah setara dengan proses membangun rumah baru. Memori yang tersusun dalam naskah sejarah (history) ditempatkan sebagai landas pijak ke masa depan, sebuah proses 'pelupaan dan pengingatan' (forgetting and rememberance) (Widyarta, 2012)

Memory as an act of being is inscribed in traces, or survivals of a past, which mark every ongoing inscription. ... Memory is discontinuous and always related to the act of being narrated. ... In short, we do not make stories out of our memories, because memories exist only within our narratives. (Santos, 2001)

\section{Kesimpulan}

Jabaran diatas menunjukkan bahwa masyarakat menyetarakan antara perbaikan rumah dengan pembangunan rumah baru. Di dalam proses perbaikan/pembangunan rumah/ bangunan baru tersebut memperhatikan aspek material dan konstruksi yang sesuai dengan keadaan geografis serta iklim lokal. Disamping itu juga ada 'harapan' yang ingin dituju dalam proses pembangunan/perbaikan tersebut di masa depan. Pemilihan material serta ukuran mempengaruhi harapan tersebut.

Proses pelupaan dan pengingatan sangat tergambar dalam proses konstruksi bangunan Jawa, sehingga pemahaman konservasi 'modern' yang hanya menitikberatkan pada 'pembekuan bangunan' (pemahaman dari teks "tidak boleh merubah apapun dari bangunan") bukanlah konsep yang cocok untuk masyakat Jawa.

Jika dikaitkan dengan pemahaman filosofis Jawa bahwa kehidupan di dunia hanya sekedar singgah untuk minum, maka konsekuensi arsitekturalnya adalah rumah/hunian adalah sebuah 'tempat singgah'/ shelter. Jadi yang dipertahankan dari nilai filsafat itu adalah cara berproses/ cara berpikir. Hal ini terbukti pada kasus Dusun Ngibikan. Hancurnya rumah/hunian mereka akibat gempa tidak 'menghancurkan' kehidupan, karena yang dipandang bukan bangunan rumah/ hunian tersebut, akan tetapi proses kehidupannya. Dengan pemahaman ini maka proses rekonstruksi dusun Ngibikan dapat berlangsung dengan cepat, sebab orientasi konservasi adalalah konservasi proses kehidupan. Jadi bagi masyarakat Jawa, konservasi mempunyai pemahaman sebagai sebuah proses bukan hasil, sebuah kegiatan aktif dan dinamis, bukan 'pembekuan' dan pasif.

\section{Daftar Pustaka}

Adiyanto, J. (Vol. 7 October 2011). Ngibikan village spirituality design in Javanese Architecture. Nakhara, Journal of Environmental Design and Planning , 89 - 102.

Armand, A., Sopandi, S., Hutama, D., Hartanto, R., \& Tardiyana, A. D. (2014). Ketukangan: Kesadaran material . Jakarta : Ikatan Arsitek Indonesia (IAI)

Derrida, J. (Vol. 25, No. 2, 1995). Archieve fever: A Freudian impression. Diacritics , 9-63.

Evans, M. (1999). Tropical design . Dalam D. Adler, Metric 
Handbook Planning and Design Data (pp. 37-1- 37-11). Oxford: Architectural Press .

Feilden, B. M. (2003). Conservation of historic building (3rd edition). Oxford: Architecture Press.

Forsyth, M. (2007). Understanding historic building conservation . Oxford: Blackwell Publishing Ltd.

Kwanda, T. (2013). Otensitas takbenda dalam tradisi konservasi di Kompleks Ki Buyut Trusmi, Cirebon. Seminar Nasional Reinterpretasi Identitas Arsitektur Nusantara. Denpasar: Universitas Udayana.

Pangarsa, G. W. (2006). Merah putih arsitektur Nusantara. Yogyakarta: Andi Offset.

Pangarsa, G. W. (2008). Arsitektur untuk kemanusiaan: Teropong visual culture atas karya-karya Eko Prawoto. Surabaya: Wastu Lanas Grafika.

Prianto, E., Bonneaud, F., Depecker, p., \& Peneau, J.-P. (Vol 1, Number 2, 2000). Tropical-humid architecture in natual ventilation efficient point of view. International Journal on Architectural Science, 80-95.

Prijotomo, J. (2004). Suasana psikologikal sebagai sarana berarsitektur: kasus primbon Jawa. Dalam J. Prijotomo, Kembara Kawruh Arsitektur Jawa (pp. 53 - 66). Surabaya: Wastu Lanas Grafika.

Prijotomo, J. (2006). (Re)-Konstruksi Arsitektur Jawa: Griya Jawa dalam tradisi tanpatulisan. Surabaya: PT. Wastu Lanas Grafika.

Prijotomo, J., \& Sulistyowati, M. (2010). Nusantara Architecture as tropical architecture. Surabaya: ITS Press.
Ricoeur, P. (1975). Phenomenology and Hermeneutics. Symposium paper to be read (pp. 85 -102). Meeting of the Western Division of the American Philosophical Association: Blackwell .

Ricoeur, P. (2004). Memory, history, forgetting . Chicago: University of Chicago Press.

Santos, M. S. (2001). Memory and narrative in Social Theory . Time \& Society, 163-189.

Silaban, F. (1983). Idealisme Arsitektur dan kenyataan di Indonesia. Dalam E. Budihardjo, Menuju Arsitektur Indonesia (pp. 75 89). Bandung: Alumni.

Tan, H., Wilson, A., \& Olver, I. (2009). Ricoeur's Theory of Interpretation: An instrument for data interpretation in Hermeneutic Phenomenology. International Journal of Qualitative Methods .

Tjakraningkrat, H. (2013). Kitab primbon Betaljemur Adammakna. Yogyakarta: CV. Buana Raya.

Widyarta, M. N. (2012). Pencitraan jati diri melalui Modernisme. Dalam PDA. Tegang Bentang: Seratus tahun perspektif arsitektur di Indonesia (hal. 6063). Jakarta: Gramedia Pustaka Utama. 